\title{
O DESAFIO PARA COMPREENDER A MORFOLOGIA CEREBRAL: DA VISUALIZAÇÃO À QUANTIFICAÇÃO
}

\author{
Silvana Regina de Melo \\ Docente Dr. do Departamento de Ciências Morfológi- \\ cas - área de anatomia humana na Universidade Esta- \\ dual de Maringá (UEM), Brasil.
}

\section{Rúbia Maria Monteiro W. de Oliveira}

Docente Dr do Departamento de Farmacologia e Terapêutica/Programa de Pós-Graduação em Ciências Farmacêuticas na Universidade Estadual de Maringá, (UEM), Brasil.

\section{Daniela Velasquez de Oliviera}

Pós-graduanda em nível de doutorado do Programa de Pós-Graduação em Ciências Farmacêuticas na Universidade Estadual de Maringá (UEM), Brasil.

\section{Tuanay Caroline Bernardi}

Graduanda em Biomedicina pela Universidade Estadual de Maringá (UEM), Brasil.

\section{Humberto Milani}

Docente Dr. do Departamento de Farmacologia e Terapêutica/Programa de Pós-Graduação em Ciências Farmacêuticas na Universidade Estadual de Maringá (UEM), Brasil.
RESUMO: O objetivo deste trabalho é estudar a morfologia neuronal a partir de modelos animais, fornecer informações biológicas difíceis de serem obtidas em humanos, permitindo estudar condições neuropsiquiátricas como doença de Alzheimer, ansiedade, dentre outras. $\mathrm{O}$ presente trabalho descreveu metodologia de estudo para cérebro de roedores, duas técnicas neuroanatômicas, Klüver-Barrera e Golgi-Cox, e seus respectivos processos de quantificação. A técnica de Klüver-Barrera permitiu visualização da substância branca e cinzenta com destaque na bainha de mielina. A técnica de Golgi-Cox, adaptada para realidade de nosso laboratório, mostrou-se eficiente para visualização de neurônios e seus prolongamentos, como dendritos e espinhas dendríticas, permitindo assim a quantificação. A partir de imagens obtidas de microscópio descreveu-se os diferentes passos para quantificação, a determinação de volume de estruturas internas cerebrais (corpo caloso e camada celular do hipocampo) assim como a quantificação das espinhas dendríticas em neurônios piramidais. Os métodos descritos e detalhados poderão ser utilizados em vários campos da neurociência.

PALAVRAS-CHAVE: Bainha de mielina; Espinhas dendríticas; Sistema nervoso central.

\section{CHALLENGES IN UNDERSTANDING BRAIN MORPHO. LOGY: FROM VISUALIZATION TO QUANTIFICATION}

ABSTRACT: Neuronal morphology is analyzed in animal models to provide biological information difficult to obtain in humans. The above makes possible the study of neuro-psychiatric, such as Alzheimer's disease, anxiety and others. Current study described methodology for rodents' brains, two neuro-anatomic techniques, Klüver-Barrera and Golgi-Cox, and their respective quantification processes. Klüver-Barrera technique visualized the white and gray matter, particularly the myelin sheath. Golgi-Cox technique, adapted for current research, was efficient to visualize neurons and their prolongations, such as dendrites and dendritic spines, with quantification. Images by microscope described the different steps for the quantification, determination of volume of the brain's internal structures (callous body and the hypocampus's cell layer) coupled to the quantification of dendritic spines in pyramid neurons. Described and detailed methods will be useful in several fields of neuroscience.

KEY WORDS: Central nervous system; Dendritic spines; Myelin sheath. 


\section{INTRODUÇÃO}

O estudo da morfologia neuronal em modelos animais de doenças do sistema nervoso central (SNC) é tão importante quanto um exame de ressonância magnética funcional, pois permite observação de alterações que, em certas condições, seriam muito difíceis ou impossíveis de serem investigadas em humanos. Diversas patologias e psicopatologias estão relacionadas às mudanças anatômicas cerebrais macro e microscópicas ${ }^{1,2}$. Além disso, estudos mostram que estruturas cerebrais como hipocampo ${ }^{3,4}$ e corpo caloso ${ }^{1,5}$ têm seu volume reduzido em indivíduos que viveram experiência de estresse crônico considerado tóxico (ex.: abuso sexual, negligência parental), sendo estas alterações morfológicas associadas a transtornos de ansiedade e/ou estresse pós-traumático. Até certo ponto, tais alterações estruturais e funcionais são passíveis de serem reproduzidas em modelos animais. Sendo assim, técnicas de baixo custo financeiro e que proporcionem boa visualização da estrutura cerebral microscópica representam valiosa ferramenta para a neurociência.

Dentre as técnicas histológicas que garantem visualização de neurônios, a pioneira técnica de Golgi descoberta em 1873 foi sendo aperfeiçoada desde então, de modo a possibilitar nítida visualização de certas ultraestruturas neuronais, a exemplo das espinhas dendríticas ${ }^{6}$ (protrusões citoplasmáticas que emergem da superfície externa do soma neuronal e dendritos, e representam o local de maior conexão e atividade sináptica) ${ }^{7}$. Por exemplo, a técnica de Golgi-Cox tem sido amplamente empregada para se investigar a relação entre comportamento e morfologia cerebral, tanto em animais de experimentação quanto em humanos ${ }^{8,9,10}$. Outra técnica muito utilizada foi proposta por Klüver e Barrera ${ }^{11}$ a qual emprega o corante Luxol fast blue ${ }^{\circledR}$ (ftalocianina cúprica azul) para visualizar fibras mielínicas (axônios e seu envoltório mielínico). Tal estrutura não pode ser visualizada pela maioria das técnicas tradicionais e agentes químicos comumente utilizados, uma vez que são incompatíveis com a composição lipídica da bainha de mielina, rica em glicofosfolipídeos e colesterol ${ }^{13}$. A alta solubilidade em fosfolipídeos do $L u$ xol fast blue explicaria sua capacidade de corar mielina ${ }^{11}$. Além disso, quando associada ao corante violeta de cresila, a técnica de Klüver-Barrera possibilita também a visualização do corpo celular (soma), inclusive o núcleo ${ }^{12}$.
A descrição de técnicas histológicas na literatura não é garantia de sucesso para outros laboratórios, uma vez que detalhes importantes nem sempre são mencionados ou até mesmo são negligenciados, dificultando sua reprodutibilidade. Portanto, o objetivo do presente trabalho foi descrever a técnica de Golgi-Cox para visualização da morfologia neuronal, inclusive as espinhas dendríticas, bem como a técnica de Klüver-Barrera com contra-coloração pelo corante violeta de cresil, para identificar e analisar o volume do hipocampo e corpo caloso. Foram descritos também métodos adequados de quantificação das espinhas dendríticas (Golgi-Cox), volume do hipocampo e corpo caloso.

\section{METODOLOGIA}

ANIMAIS

Foram utilizados três ratos Wistar machos (Rattus novergicus) com três meses de idade, mantidos em condições padrão de alojamento no Biotério Setorial do Departamento de Ciências Morfológicas da Universidade Estadual de Maringá, com iluminação de claro e escuro de 12 horas e temperatura de $22 \pm 2{ }^{\circ} \mathrm{C}$. Os animais receberam alimentação (ração padrão para roedores - Nuvilab-nuvital ${ }^{\circledR}$ ) e água ad libitum por 24 horas. Todos os procedimentos foram realizados de acordo com Comitê de Ética em Experimentação Animal da Universidade Estadual de Maringá (Protocolo 108/2012).

\section{Etapa 1 - Preparo das soluçóes}

A fim de facilitar a preparação das soluções, as proporções utilizadas foram calculadas para $1000 \mathrm{ml}$. No entanto, deve-se considerar que para um cérebro de rato, o volume de $30 \mathrm{ml}$ de solução fixativa é suficiente.

\section{Solução de Paraformaldeído 4\%}

Em um béquer de vidro, colocar $40 \mathrm{~g}$ de paraformaldeído e completar com $1000 \mathrm{ml}$ de água destilada. Levar ao agitador com aquecimento até $60{ }^{\circ} \mathrm{C}$, e então adicionar gotas de hidróxido de sódio $(\mathrm{NaOH})(5 \mathrm{M})$ até a solução ficar transparente. 
Solução Salina 0,9 \%

Em um béquer de vidro colocar $9 \mathrm{~g}$ de cloreto de sódio $(\mathrm{NaCl})$, completar com $1000 \mathrm{ml}$ de água destilada e agitar até dissolução completa.

\section{Solução de Golgi}

\section{Solução A}

Em béquer de vidro colocar $18,7 \mathrm{~g}$ de dicromato de potássio $\left(\mathrm{K}_{2} \mathrm{CR}_{2} \mathrm{O}_{7}\right)$, completar com $375 \mathrm{ml}$ de água destilada, e agitar durante 30 minutos, cuidando para não ultrapassar $60^{\circ} \mathrm{C}$.

\section{Solução B}

Em béquer de vidro colocar $18,7 \mathrm{~g}$ de cloreto de Mercúrio (II) $\left(\mathrm{HgCl}_{2}\right)$, completar com $375 \mathrm{ml}$ de água destilada, agitar durante 30 minutos, cuidando para não ultrapassar $100{ }^{\circ} \mathrm{C}$.

\section{Solucão C}

Em béquer de vidro colocar $15 \mathrm{~g}$ de cromato de potássio $\left(\mathrm{K}_{2} \mathrm{CrO}_{4}\right)$ e completar com $300 \mathrm{ml}$ de água destilada e agitar sem aquecer.

Para solução de Golgi mistura-se solução A com B e por último a C e em seguida adiciona-se $750 \mathrm{ml}$ de água destilada. O armazenamento é feito em garrafa de vidro escuro (recomenda-se cobrir com saco preto por 5 dias em local escuro em temperatura ambiente). Após esse período filtra-se com papel filtro em local com pouca luminosidade e manter em local escuro e temperatura ambiente. Tempo de vida da solução (1 a 6 meses). Por ter alta toxicidade, deve ser preparada dentro de capela e com uso de EPIs.

\section{Solução de amônia (3:1)}

Em béquer de vidro coloca-se $200 \mathrm{ml}$ de amônia e completa-se com $100 \mathrm{ml}$ de água destilada.

Solução de Rapid fix
Em béquer de vidro coloca-se $150 \mathrm{ml}$ de Kodak rapid fix ${ }^{\circledR}$ (Solução A para filme e papel) e completa-se com $150 \mathrm{ml}$ de água destilada.

\section{Solução de Luxol fast-blue 0,1\%}

Em béquer de vidro coloca-se $0,1 \mathrm{~g}$ de $\operatorname{Luxol}{ }^{\circledR}$ fast blue MBSN e completa-se com $100 \mathrm{ml}$ de álcool 95\%, e dissolve com auxílio de agitador. E em seguida acrescenta-se $0,5 \mathrm{ml}$ de ac. acético $10 \%$ e filtra-se antes do uso.

\section{Solução de Carbonato de lítio}

Em béquer de vidro coloca-se $0,05 \mathrm{~g}$ de carbonato de lítio $\left(\mathrm{Li}_{2} \mathrm{CO}_{3}\right)$ e completa-se com $100 \mathrm{ml}$ de água destilada, e dissolve com auxílio de agitador.

\section{Solução de violeta de cresila $0.1 \%$}

Em béquer de vidro coloca-se $0,1 \mathrm{~g}$ de cresil violeta $\left(\mathrm{C}_{19} \mathrm{H}_{18} \mathrm{ClN}_{3} \mathrm{O}\right)$, completa-se com $100 \mathrm{ml}$ de água destilada e dissolve sob agitação por 30 minutos aquecendo-se até alcançar $60^{\circ} \mathrm{C}$. Adicionado 5 gotas de ácido acético glacial $10 \%$ e filtra-se antes do uso.

\section{Solução de sacarose $30 \%$}

Em béquer de vidro coloca-se $300 \mathrm{~g}$ de sacarose $\left(\mathrm{C}_{12} \mathrm{H}_{22} \mathrm{O}_{11}\right)$ e completa-se com $1000 \mathrm{ml}$ água destilada, e agita-se até dissolução.

\section{Solução de gelatinização}

Em béquer de vidro coloca-se $0,5 \mathrm{~g}$ de gelatina incolor e completa-se com $100 \mathrm{ml}$ de água destilada, e agita-se até $60{ }^{\circ} \mathrm{C}$. Deixar esfriar até temperatura de aproximadamente $40{ }^{\circ} \mathrm{C}$ e adiciona-se $0,05 \mathrm{~g}$ de sulfato de cromo $\left(\mathrm{KCrS}_{2} \mathrm{O}_{8}\right)$, que atua como antifúngico. Após dissolver com auxílio de agitador, essa solução é filtrada com auxílio de papel de filtro.

\section{Etapa 2 - Perfusão e Fixação do cérebro in situ}

$O$ animal deve ser profundamente anestesiado por meio de injeção intraperitonial de tiopental $(100 \mathrm{mg} /$ 
$\mathrm{kg}$ ), precedida (cerca de 5 minutos antes) pela injeção de lidocaína (10 mg/kg) aplicada na mesma região que recebeu o tiopental. Ambas as injeções são aplicadas em volume de $(0,1 \mathrm{~mL} / 100$ gramas de peso). A eficácia da anestesia é aferida pelo teste de pinçamento da ponta da cauda. A ausência de qualquer reflexo por parte do animal indica que a anestesia foi implantada com sucesso. O animal é então posicionado em decúbito dorsal, estando as patas imobilizadas, para o procedimento de perfusão intracardíaca, conforme técnicas de rotina ${ }^{14}$. Para realização da técnica de Klüver-Barrera, utiliza-se solução salina 0,9\% seguido de solução de paraformaldeído 4\%. Para técnica de Golgi-Cox, a perfusão é realizada apenas com solução salina $0,9 \%$. Após perfusão transcardíaca, a cabeça do animal é retirada e mantida em gelo por 30 minutos. Em seguida o cérebro é removido cuidadosamente, lavado com água destilada e seccionado com dois cortes coronais, um na região do bulbo olfatório e outro na altura do colículo inferior para promover melhor pós-fixação.

\section{Etapa 3 - Pós-fixação_}

Para técnica de Klüver-Barrera, o cérebro é pós-fixado em $30 \mathrm{ml}$ de solução de paraformaldeído 4\% durante 48 horas em temperatura ambiente. Para técnica de Golgi-Cox o cérebro é pós-fixado em $30 \mathrm{ml}$ de solução de Golgi utilizando-se recipiente com tampa de plástico escuro, e mantido em estufa a $37{ }^{\circ} \mathrm{C}$ por 24 horas. Após este tempo, coloca-se no agitador (em velocidade lenta) por 2 horas e em seguida substitui-se por nova solução de Golgi, na qual permanece por mais 19 dias em temperatura ambiente em ambiente escuro.

\section{Etapa 4 - Crioproteção e Congelamento}

Transfere-se o cérebro para solução de sacarose $30 \%$ por período de 24 horas. Troca-se esta solução por outra nova, na qual o cérebro permanece até sua precipitação ao fundo do recipiente (cerca de 20 dias), à temperatura ambiente.

\section{Congelamento}

Após crioproteção, o cérebro é congelado por imersão em N-hexano ( $40 \mathrm{ml}$ ) durante aproximadamente 10 segundos, com auxílio de béquer de vidro mantido em caixa de isopor contendo nitrogênio líquido. Em seguida os cérebros são levados ao criostato para obtenção de cortes coronais, com expessuras de $40 \mu \mathrm{m}$ ou $100 \mu \mathrm{m}$ que são utilizadas para coloração de Klüver-Barrera ou Golgi-Cox, respectivamente.

\section{Etapa 5 - Microtomia e Impregnação do tecido}

\section{Preparação das lâminas}

Para melhor aderência das secções histológicas nas lâminas de vidro, utiliza-se o seguinte processo. As lâminas previamente limpas e secas são colocadas em cuba histológica e mergulhadas na solução de gelatinização por 10 min. Após escorrer são deixadas para secar em suporte de lâminas na posição vertical, em temperatura ambiente durante 5 dias e protegidas de poeira.

\section{Microtomia}

Para técnica de Klüver-Barrera são obtidas secções com $40 \mu \mathrm{m}$, e após o primeiro corte coletado aleatoriamente, nos cortes subsequentes, a $5^{\mathrm{a}}$ secção é coletada e disposta sobre lâmina conforme Figura 1A. Ou seja, a cada $200 \mu \mathrm{m}$ (4 secções de $40 \mu \mathrm{m} / \mathrm{cada}$ ), utiliza-se uma secção (a $\left.5^{\mathrm{a}}\right)$ para análise. Este procedimento deve-se repetir ao longo de toda extensão cerebral que se deseja examinar. Esta metodologia garante uma amostragem sistemática, premissa básica para determinação do volume da estrutura de acordo com princípio de Cavalieri ${ }^{15}$.

Para técnica de Golgi-Cox, são obtidas secções coronais com $100 \mu \mathrm{m}$ de espessura e a partir da primeira secção considerada, uma a cada cinco é coletada aleatoriamente e disposta sobre a lâmina (Figura 1B). A metodologia assegura que todas as regiões tenham a mesma chance de serem amostradas. Após colocar os cortes sobre a lâmina, um papel toalha umedecido é disposto sobre os cortes de tecido cerebral, pressionando-se levemente com a palma das mãos. As lâminas contendo os cortes são armazenadas em cubas de vidro e envolvidas com tecido umedecido em água. São mantidas em caixa de plástico escuro com tampa, e mantida em ambiente escuro (temperatura ambiente) por 24 horas em média (12 a 48 horas). Esta etapa garante a aderência dos cortes nas lâminas. 

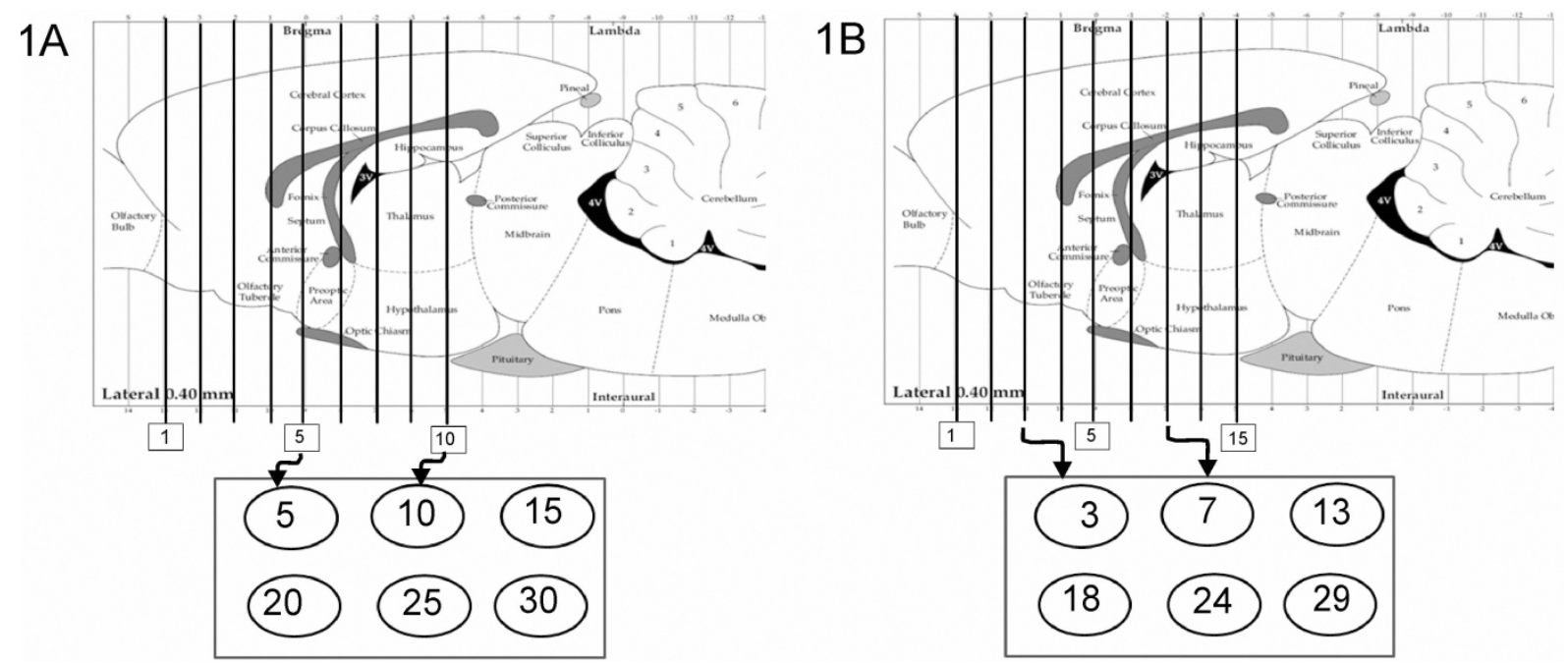

Figura 1. Figura representativa evidenciando cortes coronais e a disposição sistemática (1A) nas lâminas para análise do volume e disposição (1B) para análise aleatória.

Impregnação do tecido nervoso pela técnica de Klüver-Barrera (observação da bainha de mielina e núcleos celulares)

O protocolo aqui descrito foi adaptado principalmente de Bittencourt e Elias (2007), e otimizado para cérebro de rato preparado com os procedimentos descritos anteriormente.

Após microtomia os cortes congelados são secos em estufa a $37^{\circ} \mathrm{C}$ (no mínimo 18 horas e no máximo 24 horas). Em seguida, clareados em xilol (2 cubas, sendo 3 minutos em cada), hidratados em concentrações decrescentes de álcool (álcool 100\%, e duas cubas de álcool 95\%) com 5 minutos em cada. Os cortes são então imersos em cuba contendo solução de Luxol fast blue ${ }^{\circledR}$, que é isolada com auxílio de tampa de vidro e mantida em estufa a $60{ }^{\circ} \mathrm{C}$ por 2 horas. Após 30 minutos, em temperatura ambiente, os cortes são mergulhados na seguinte sequência de cubas contendo álcool 95\%, água destilada, solução de carbonato de lítio $0.05 \%$ e álcool $70 \%$. Nas duas últimas etapas deverá ocorrer a diferenciação do tecido, quando a substância branca cerebral (fibra mielínica) deverá expressar um tom azul, em contraste à ausência de coloração da substância cinzenta (somas neuronais). Em seguida coloca-se as lâminas em cuba contendo solução de violeta cresil $0.1 \%$ por 6 minutos em estufa a $50{ }^{\circ} \mathrm{C}$. Após 10 minutos em temperatura ambiente, as lâminas são colocadas em água destilada e em seguida procede-se a desidratação dos cortes em concentrações crescentes de álcool (duas vezes em álcool 95\% e em seguida em álcool $100 \%$ durante 3 minutos cada. Finalmente as lâminas devem ser clareadas em xilol ( 2 cubas, sendo 3 minutos em cada) e cobertas com resina Permount ${ }^{\circledR}$ e lamínula.

Impregnação do tecido nervoso pela técnica de Golgi-Cox (observação de dendritos e espinhas dendríticas)

O protocolo segue em duas fases: $1^{\mathrm{a}}$ ) fase escuro e $2^{a}$ ) fase claro. Na fase escuro, as lâminas devem ser protegidas completamente da luz. Esta fase deve ser realizada em capela. A cuba de lâminas previamente preparada é colocada na seguinte sequência de substâncias: água destilada (1 minuto), solução de amônia (40 minutos), água destilada (5 minutos), solução de Kodak Fix para filme ${ }^{\circledR}$ (40 minutos). Na fase claro, a cuba de lâminas é colocada na seguinte sequência de substâncias: duas vezes em água destilada (1 minuto cada), sequência crescente de álcoois (50\%, 70\%, 95\%, 100\%, 100\% e 100\%, 5 minutos cada). Finalmente são clareadas em xilol (2 cubas, 10 minutos cada) e cobertas com resina e lamínula, deixadas para secagem na posição horizontal e no escuro, e seladas com esmalte após secagem. 


\section{Etapa 6 - Métodos de quantificação}

\section{Determinação de volume (corpo caloso e hipocampo)}

Utilizando cérebro seccionado no sentido frontal, cujas lâminas foram preparadas em Klüver-Barrera, a região escolhida para determinação do volume ${ }^{14}$ deve ter como base um atlas (ex.: Paxinos \& Watson ${ }^{16}$ ).

Com auxílio de um microscópio acoplado a câmara de vídeo, as imagens são captadas, digitalizadas em um computador e projetadas em monitor de vídeo. Sobre a tela do monitor coloca-se sistema teste contendo pontos (Figuras 2B e 2E).
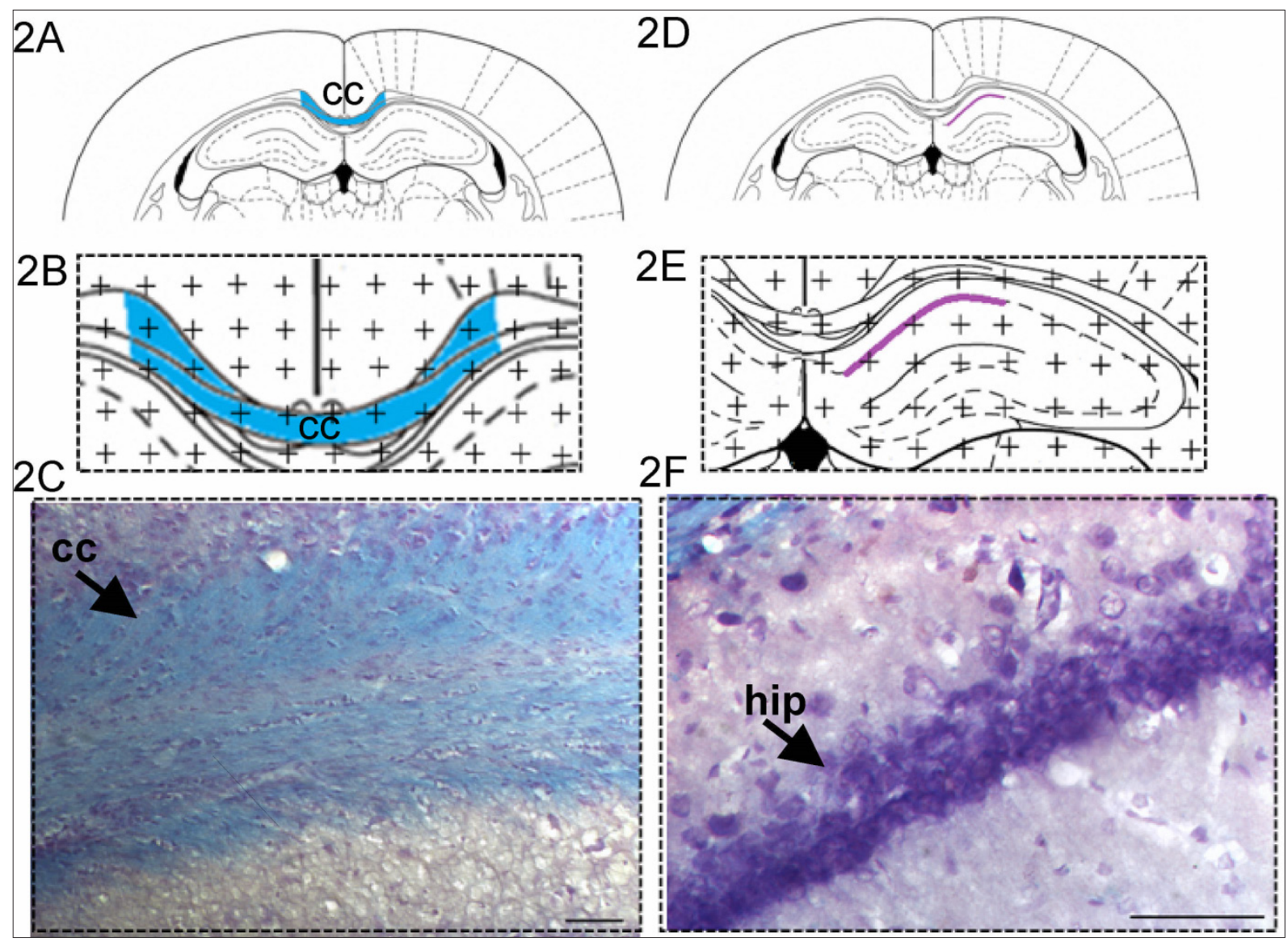

Figura 2. Representação da região do corpo caloso (cc) analisada (2A, 2B, 2C), e camada piramidal do hipocampo (hip) da região CA1 (2D, 2F) com simulação do sistema teste utilizado (2B, 2D). As regiões do corpo caloso (2C) e hipocampo (2F) que foram coradas pela técnica de Klüver-Barrera (2C). Barra $=50 \mu \mathrm{m}$

Este procedimento é repetido em todas as secções determinadas e os pontos que tocam na estrutura que se deseja analisar (corpo caloso ou hipocampo) são contados. Utiliza-se assim o método da planimetria, que objetiva medir uma área em um sistema plano usando pontos com áreas conhecidas. A associação da planimetria com o princípio de Cavalieri ${ }^{17}$ possibilita determinar o volume da estrutura a partir da fórmula: $\mathbf{V}=\mathrm{T}$. $\mathbf{A}$, onde $\mathrm{V}=$ volume, $\mathrm{T}=$ somatória de secções utilizadas, $\mathrm{A}=$ área dos cortes. Para determinar o valor de T, utiliza-se a seguinte fórmula $\mathbf{T}=\boldsymbol{\Sigma}$ secções. $\mathbf{t}$ onde, $\mathrm{T}=\Sigma$ corresponde à somatória de secções utilizadas e $\mathbf{t}$ corresponde à espessura do corte entre os intervalos determinados. Por exemplo, se a espessura do corte foi de $5 \mu \mathrm{m}$ e o intervalo de secções utilizado foi 5 , então $t=25 \mu \mathrm{m}$. E o valor de $\mathbf{A}=\boldsymbol{\Sigma} \mathbf{P} . \mathbf{d}^{2}$, onde $\Sigma$ P corresponde à somatória de pontos que tocaram no sistema teste e $\mathbf{d}$ é a distância em micrômetros entre dois pontos do sistema teste. 


\section{Quantificação das espinhas dendríticas}

Um neurônio piramidal localizado na área que se deseja quantificar as espinhas é selecionado com base nos seguintes critérios: corpo celular e dendritos completamente corados, não ter sobreposição com outro dendrito ou vaso sanguíneo. Em seguida, com ampliação de 40x identifica-se dendritos apicais e basilares, e com ampliação de 100x realiza-se a identificação das espinhas e com auxílio de uma ocular milimetrada (olympus), considera-se uma distância pré-determinada (por exemplo, $50 \mu \mathrm{m}$ do dendrito apical e mensura-se a quantidade de espinhas presentes neste segmento. O mesmo procedimento é realizado nos dendritos basilares (Figura 3) ${ }^{18}$.

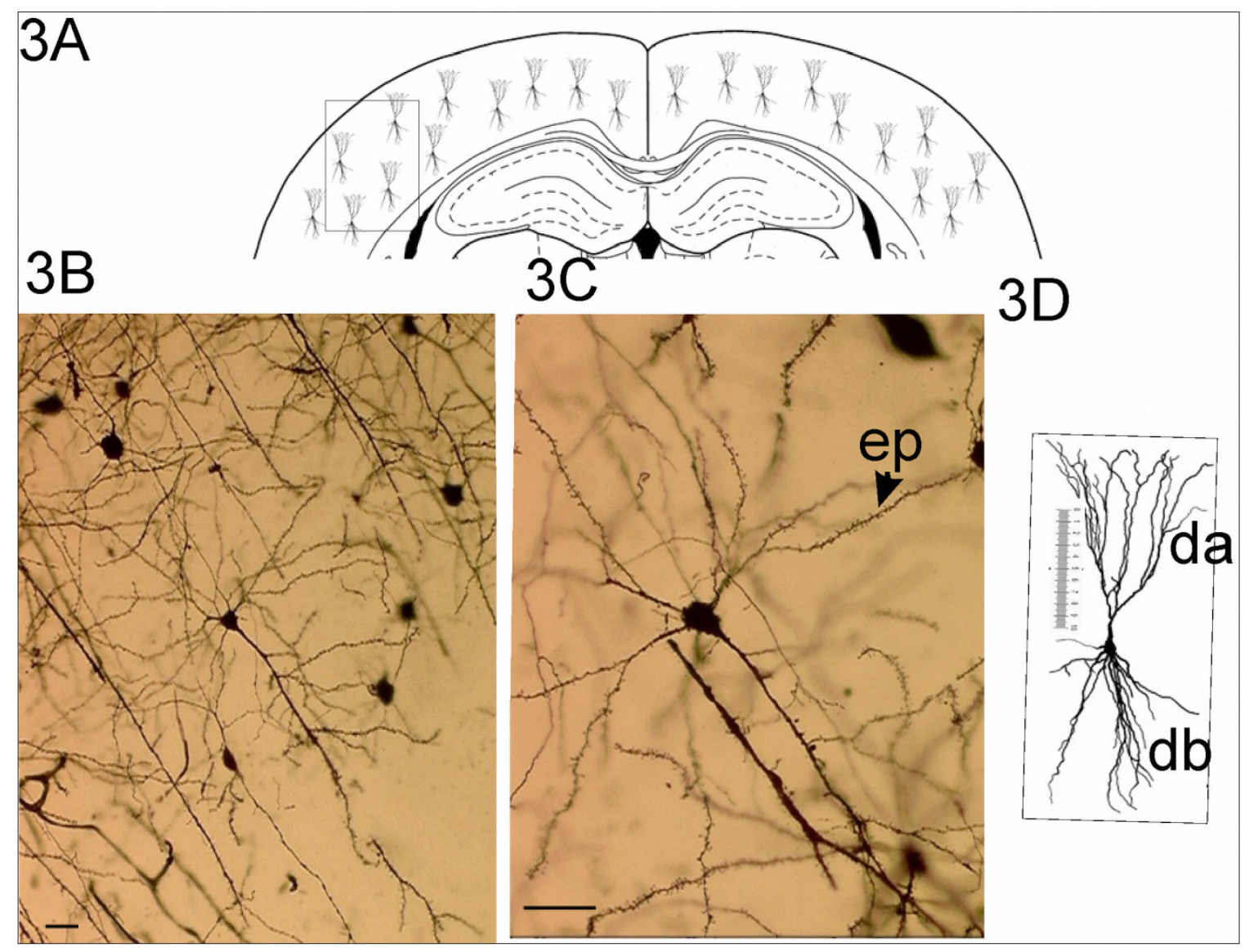

Figura 3. Representação da região córtex (3A), evidenciando neurônios piramidais (3B, C) corados pela técnica de Golgi-Cox, e método de quantificação das espinhas dendríticas (ep) dos dendritos basilares (db) e apicais (da) (3D) por meio de régua milimetrada. Barra $=10 \mu \mathrm{m}$. 


\section{RESULTADO e DISCUSSÃO}

Neste estudo foi descrito em detalhes protocolo para as técnicas de Klüver-Barrera e Golgi-Cox. Apesar de serem consideradas clássicas, a reprodução a partir dos manuais não garante seu sucesso na prática. Nosso empenho nestas tradicionais neurotécnicas foi devido seu menor custo financeiro em relação a outras neurotécnicas, e as informações valiosas que oferecem para estudo do SNC.

$\mathrm{Na}$ etapa de congelamento perdeu-se um cérebro, pois o mesmo sofreu rachadura, mostrando que essa etapa deve ser feita com critério de tempo, que neste caso foram 10 segundos, intervalo de tempo considerado confiável. O protocolo para técnica de Klüver-Barrera, com a contra-coloração pelo violeta cresil promoveu coloração de qualidade para estudo do SNC. A etapa de diferenciação foi o ponto mais crítico da técnica, devendo ser feita sob a luz e com auxílio de microscópio. Tal procedimento assegurou distinção de substância branca e cinzenta (Figura 2), o que favorece a observação segura da substância, tal como corpo caloso.

Para determinar o volume de uma estrutura interna, utilizou-se princípios já estabelecidos da estereologia ${ }^{14}$, descritos aqui para o SNC. A etapa de coleta de secções, e sua organização na lâmina, foi criteriosa, premissa básica para não ter viés na determinação do volume. Com imagens de qualidade da substância branca é possível analisar desde o volume do corpo caloso, uma estrutura interna até o volume total da substância branca no cérebro. A contra coloração com violeta cresil aumenta as possibilidades de análise científica quantitativa, pois permite a visualização confiável de núcleos de células gliais presentes na substância branca. Além disso, a técnica com contra coloração permite a observação de componentes da substância cinzenta, possibilitando por exemplo estudo da espessura cortical, como exemplo da camada piramidal do hipocampo, exemplificado neste trabalho. Pode-se afirmar que a técnica ofereça economia financeira, promove a menor utilização de animais, e otimiza o tempo dos envolvidos na pesquisa científica.

Notamos que há dificuldade de se estabelecer o limite do corpo caloso total nas secções frontais, e sugerimos que ao utilizar este tipo de secção é importante basear-se no atlas para definir limites regionais. Por exemplo, pode-se considerar a análise de regióes específicas do corpo caloso, tais como joelho, corpo ou esplênio do corpo caloso utilizando-se a secção com semelhança anatômica à secção correspondente ao Bregma definido pelo atlas. Para o hipocampo é possível analisar seu volume total ou volume de camadas, tais como volume da camada piramidal. Para determinação do volume de qualquer estrutura é necessário a visualização no monitor, e, portanto, isso requer objetivas de aumento $1 \mathrm{X}$ ou $2 \mathrm{X}$.

O protocolo adaptado para Golgi-Cox ${ }^{6,19}$ apresentado neste estudo também se mostrou eficiente na identificação dos neurônios piramidais, e apesar da técnica também promover a coloração de células gliais e vasos sanguíneos, foi possível fazer a identificação segura dos neurônios devido à impregnação dos prolongamentos neuronais e das espinhas dendríticas (Figura 3).

Com a impregnação adequada dos dendritos e respectivas espinhas dendríticas, é possível realizar a quantificação destas com o método descrito anteriormente (Figura 3D). Tal informação é valiosa para estudos comparativos da neurociência, pois permite avaliar se regiões estão sendo mais ativadas ou não, conforme o estímulo aplicado, o transtorno ou a doença mental. Além disso, as alterações detectadas nas espinhas dendríticas representam uma das mais importantes evidências científicas da neuroplasticidade cerebral. No entanto, a técnica só é possível se houver equipamentos básicos como, por exemplo, criostato, o que representa uma barreira para muitos laboratórios uma vez que tal equipamento e sua manutenção são financeiramente caros, e a utilização de reagentes com metais pesados como mercúrio exige maiores cuidados.

\section{CONCLUSÃO}

O desafio para compreender o funcionamento do cérebro está diretamente relacionado à compreensão da sua morfologia. Este trabalho se contribui no sentido que apresenta detalhadamente os passos para tal estudo, pois há esta lacuna na literatura. Do processo de preparação do cérebro até a etapa final de quantificação, descrevemos aqui dois métodos de coloração e duas técnicas de 
quantificação. Apesar de delicado, as técnicas de coloração e métodos de quantificação são viáveis do ponto de vista financeiro e representam ferramenta valiosa no estudo do SNC, desde a neurobiologia dos transtornos mentais aos efeitos da criação em ambientes enriquecidos.

\section{AGRADECIMENTOS}

À Coordenação de Aperfeiçoamento de Pessoal de Nível Superior (CAPES) pelo apoio financeiro para realização do estágio de pós-doutorado e ao Prof. Dr. Bryan Kolb da Universidade de Lethbridge pela colaboração indireta neste artigo.

\section{REFERÊNCIAS}

1. De Bellis MD, Keshavan MS, Shifflett H, Iyengar S, Beers SR, Hall J, Moritz G. Brain structures in pediatric maltreatment-related posttraumatic stress disorder: A sociodemographically matched study. Biol Psychiatry. 2002;52:1066-78.

2. Teicher MH, Tomoda A, Andersen SL. Neurobiological consequences of early stress in chidhood maltreatment: are results from human and animal studies comparable? Annals New York Academy of Sciences. 2006;1071:313-32.

3. Bessa JM, Ferreira D, Melo I, Marques F, Cerqueira JJ, Palha JA, Almeida OFX, Sousa N. The mood-improving actions of antidepressants do not depend on neurogenesis but are associated with neuronal remodeling. Mol. Psychiatry. 2009;14:764-73.

4. Yun J, Koike H, Ibi D, Toth E, Mizoguchi H, Nitta A, Yoneyama M, Ogita K, Yoneda Y. Chronic restraint stress impairs neurogenesis and hippocampus-dependent fear memory in mice: possible involvement of a brain-specific transcription Npas4. J Neurochemistry. 2010;114:1840-51.

5. Kitayama N, Brummer M, Hertz L, Quinn S, Kim Y, Bremmer D. Morphologic alterations in the corpus callosum in abuse-related posttraumatic stress disorder. J. Nerv Ment Dis. 2007;195(12):1027-29.

6. Gibb R, Kolb B. A method for vibratome sectioning of Golgi-Cox stained whole rat brain. J Neurosci Methods. 1998;79:1-4.

7. Spruston N. Pyramidal neurons: dendritic structure and synaptic integration. Nat Rev Neurosci. 2008;9 (3):206-21.

8. Rosoklija GB, Petrushevski VM, Stankov A, Dika A, Jakjovski Z, Pavlovski G, Davcheva N, Lipkin R, Schnieder T. Reliable and durable Golgi staining of brain tissue from human autopsies and experimental animals. J Neurosc Methods. 2014;15(230):20-9.

9. Muhammad A, Kolb B. Maternal separation altered behavior and neuronal spine density without influencing amphetamine sensitization. Behav Brain Res. 2011;223:7-16.

10. Melo SR, Antoniazzi TD, Hossain S, Kolb B. Neonatal stress has a long-lasting sex-dependent effect on anxiety-like behavior and neuronal morphology in the prefrontal cortex and hippocampus. Dev Neuroscience. 2018;40:93-103.

11. Klüver H, Barrera EA. A method for the combined staining of cells and fibers in the nervous system. J Neuropathol Exp Neurol. 1953;12:400-3.

12. Horta Junior JA, Sita LV. Métodos para o estudo de citoarquitetura. In: Bittencourt JC, Elias CF. Métodos em Neurociências. São Paulo: Editora Roca; 2007. p. 17-32.

13. Simons M, Trajkovic K. Neuron-glia communication in the control of oligodendrocyte function and myelin biogenesis. J Cell Science. 2006;119:4381-89.

14. Nogueira MI, Barbieri C, Vieira R, Marques ER, Moreno JEH. A practical devide for histological fixative procedures that limits formaldehyde deleterious effectes in laboratory environments. J Neurosc Methods. 1997;72:65-70.

15. Mandarim-de-Lacerda CA. Métodos quantitativos em Morfologia. Rio de Janeiro: EdUERJ, 1995.

16. Paxinos $G$, Watson $C$. The rat brain in stereotaxic coordinates. Sydney: Academic Press, 1998.

17. Mandarim-de-Lacerda CA. Stereological Tools in Biomedical Research. Anais da Academia Brasileira de Ciências, 2003;75(4):1-19.

18. Lin JB, Zheng CJ, Zhang X, Chen J, Liao WJ, Wan Q. Effects of tetramethylpyrazine on functional re- 
covery and neuronal dendritic plasticity after experimental stroke. Evidence-Based Complementary and Alternative Medicine. 2015;394926:1-10.

19. Zaqout S; Kaindl A. M. Colgi-Cox staining step by step. Frontiers in Neuroanatomy. 2016;10:1-7.

Recebido em: 25/10/2018

Aceito em: 28/12/2018 